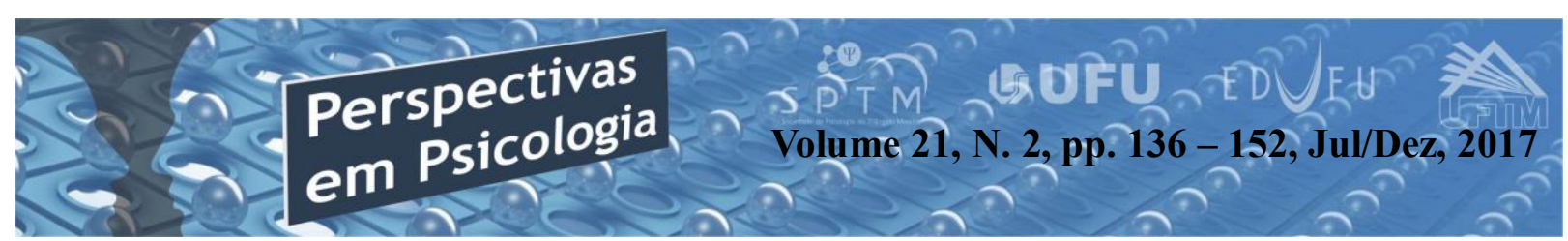

\title{
TRIBOS URBANAS NO ESPAÇO ESCOLAR E O PAPEL DO ORIENTADOR EDUCACIONAL
}

\author{
Anderson Oramisio Santos \\ (Universidade Federal de Uberlândia - UFU, Uberlândia - MG)
}

\begin{abstract}
Resumo
O objetivo desse artigo é analisar os agrupamentos de tribos urbanas no espaço educacional e ao mesmo tempo ressaltar o seu desenvolvimento em sala de aula e os mecanismos empregados em sua composição e conservação. As tribos urbanas podem ser entendidas como formas de organização juvenil nas sociedades contemporâneas muito corriqueiras nas grandes cidades e que se caracterizam por compartilhar ideais, podendo estar inseridas nos diferentes espaços sociais. É a partir da socialização que a pessoa se insere nesses grupos, podendo referir-se a mais de um, de acordo com os espaços que convive. A orientação pedagógica, ora limitada à área educacional, tem-se desenvolvido cada vez mais. A função deste vem sendo examinada atualmente, como consequência das modificações gradativas que acontecem na essência da sociedade. Trata-se de uma pesquisa bibliográfica apoiada em estudiosos que debruçam sobre o tema. Constatou-se que a orientação educacional/pedagógica, em quaisquer dos seus aspectos, deve apresentar em vista a importância do fim precípuo a que a escola se designa: a concepção de condições e de circunstâncias adequadas ao bem estar emocional do aluno e o seu desenvolvimento em todos os significados: cognitivo, psicomotor e afetivo, a fim de que o mesmo adquira aptidões, conhecimentos e costumes que lhe admitam fazer face às precisões fundamentais e existenciais.
\end{abstract}

Palavras-chave: tribos urbanas; orientador educacional; espaço escolar; jovens; identidade.

\section{Abstract \\ Urban Tribes in School Space and the Role of Educational Guidelines}

The aim of this paper is to analyze groups of urban tribes in the educational space and at the same time emphasize its development in the classroom and the mechanisms employed in its composition and conservation. The urban tribes can be understood as forms of youth organization in very ordinary contemporary societies in big cities and which are characterized by sharing ideals and may be inserted in different social spaces. It socialization from the person to insert these groups may refer to more than one, according to the spaces which coexists. The tutoring, now limited to the education sector, has developed more and more. The function of this is currently being examined, as a result of gradual changes occurring in the core of society. This is a bibliographic research supported by scholars who pore over the issue. It was found that the educational / tutoring in any of its aspects, must submit to the importance of the end preciput that the school is called: the design conditions and circumstances appropriate to the emotional well-being of the student and their development in all meanings: cognitive, psychomotor and affective, so that the applicant can acquire skills, knowledge and habits which allow him to meet his fundamental and existential details.

Keywords: urban tribes; educational advisor; school space; young people; identity. 


\section{Introdução}

A escola percebida como grupo social é um ambiente ativo e complexo em que grupos de alunos se constituem a partir de fatores como idade, sexo, status, interesses, etc. Portanto, a uma análise sociológica admite analisar e destacar a importância da sociabilidade juvenil a partir de instituições clássicas como escola, igreja, família, etc., contudo também de formas atuais de agrupamentos como as torcidas organizadas ${ }^{1}$, os punks ${ }^{2}$, emos $^{3}$, funkeiros ${ }^{4}$, LGBTs $^{5}$, e outros grupos similares.

Como em qualquer outro agrupamento, também os grupos de jovens se constituem por união a ideais artísticos, políticos, religiosos, etc. Esse ajuntamento acontece no esforço de se individualizar de outras gerações, contudo também de anunciar personalidades. É na procura por identidade e identificação que os jovens compartilham de determinados grupos que aparecem do vai e vem do dia-a-dia onde a

${ }^{1}$ É a denominação dada a uma associação de torcedores de um determinado clube esportivo no Brasil.

${ }^{2} \mathrm{O}$ estilo punk surgiu em 1975 como mais uma manifestação juvenil semelhante aos da década de 50 e 60: o objetivo do movimento era a afirmação de um estilo, sem envolver com questões éticas, políticas ou sociais.

${ }^{3}$ Emo vem do termo emotional hardcore, um estilo de musica dos anos 80 pertencente ao punk rock caracterizado pela musicalidade melódica. Tem casualidade os põe em contato.

A educação apresenta papel fundamental em proporcionar a todos os cidadãos, a entrada ao conhecimento e o desenvolvimento de competências e habilidades, ou seja, a possibilidade de compreensão do conhecimento historicamente determinado pela humanidade e de seu emprego no exercício real da cidadania.

O Orientador Educacional age como um educador, indagando e colaborando segundo as precisões do grupo. É um guia que distingue e aceita as diferenças entre os sujeitos, consegue enxergá-las em seu contexto, tenta apresentar um ambiente instigante e seguro, vincula os diversos segmentos de uma organização, resultando em laboriosidade, pois despertou a colaboração e a comunicação a partir dos relacionamentos interpessoais.

As tribos urbanas são constituídas por pequenos grupos que apresentam como finalidade principal constituir redes de amigos com baseamento em interesses

origem na palavra em inglês emotion ou emotional (emoção ou emocional). Emo é também como uma cultura alternativa, um estilo de vida, que se propagou pelo Brasil e pelo mundo.

${ }^{4} \mathrm{E}$ uma subcultura brasileira que teve origem no estado do Rio de Janeiro e se espalhou pelo resto do país ao passar dos anos. A subcultura começou nos anos 80, desde o começo do gênero musical chamado "funk carioca", e ainda existe atualmente. ${ }^{5}$ Lésbicas, Gays, Bissexuais, Travestis, Transexuais e Transgêneros. 
comuns. Essas agregações exibem um consenso de pensamentos, costumes e maneiras de se vestir entre adolescentes. A expressão tribo urbana foi criada pelo sociólogo francês Michel Maffesoli, que principiou empregá-la nas suas pesquisas a partir da década de 80 e ganha força com a publicação do seu livro "O Tempo das Tribos: O declínio do individualismo nas sociedades de massa".

Ao observar a história, percebe-se que muitas manifestações de repúdio e revolta com os modelos dominantes se ofereceram com o agrupamento de pessoas que tinham o mesmo interesse. $\mathrm{E}$ esses jovens se agrupam por convicção ou são assim para serem notados e notados numa sociedade onde o anonimato é o maior receio. A morte da identidade pessoal gerada pela sociedade contemporânea e seus aparatos não é o fim. Ainda existe, na alma do jovem, a capacidade de combater e contradizer, mesmo que à margem do normal, na oposição da sociedade. O sentimento de vazio e de contrariedade existido pelo jovem da época presente pode levar a uma aversão diante do mundo opressor levando ao surgimento das tribos urbanas.

Fazer analogias entre escola e diversidade que existe entre os jovens está se tornando cada vez mais importante para a pesquisa educacional. Um novo período vem-se configurando no quadro de produção teórica que debate a relação entre educação e sociedade. Esse momento tem nascido a partir da ação e do interesse de pesquisadores, profissionais da educação e integrantes de movimentos sociais, que vêm ajuizando sobre diversas dimensões do fenômeno educativo. Assim, pode-se ressaltar que as tribos urbanas fazem partes desses movimentos sociais, contudo que poucas vezes são tratadas ou percebidas nas perspectivas do campo da educação.

O objetivo desse artigo é analisar os agrupamentos de tribos urbanas no espaço educacional e ao mesmo tempo ressaltar o seu desenvolvimento em sala de aula e os mecanismos empregados em sua composição e conservação, além de discutir o papel do orientador educacional diante esse fenômeno social.

As tribos urbanas podem ser entendidas como formas de organização juvenil nas sociedades contemporâneas muito corriqueiras nas grandes cidades e que se caracterizam por compartilhar ideais, podendo estar inseridas nos diferentes espaços sociais. É a partir da socialização que a pessoa se insere nesses grupos, podendo referir-se a mais de um, de acordo com os espaços que convive.

A modernidade é um conjunto de mudanças acontecidas a nível mundial, resultantes da ação do homem e vinculadas a um complexo de instituições econômicas e políticas. O dinamismo das sociedades 
contemporâneas, estimulado pelas inovações tecnológicas foi alentado nas modernas sociedades de consumo. É, assim sendo, o estilo de vida atual que modifica as relações na medida em que adapta o cotidiano. O desenvolvimento industrial acarretou consigo a propagação da indústria cultural, novos bens de consumo, desenvolvimento dos meios de comunicação, diminuição da jornada de trabalho e a diversificação de bens de diversão da cultura de massa no tempo de lazer dos jovens.

As sociedades de consumo e a indústria cultural colaboram para a apropriação da definição de ser jovem; mito reportado nos meios de comunicação e em especial na internet. Para se reconhecer melhor um aluno e orientá-lo de um modo mais adequado, é imprescindível estudá-la em sua intensidade. Sendo assim, é indispensável contar com distintos pontos de vista e aptidões profissionais. Em virtude das transformações socioeconômicas e culturais acontecidas na sociedade brasileira, a escola teve de reformular suas funções habituais, redefinir a sua função e instituir novos serviços aumentando, assim, o número de indivíduos envolvidos no processo educativo.

A orientação pedagógica, ora limitada à área educacional, tem-se desenvolvido cada vez mais. A função deste vem sendo examinada atualmente, como consequência das modificações gradativas que acontecem na essência da sociedade. $\mathrm{O}$ profissional deste campo durante muito tempo agiu apenas no espaço escolar, onde competia a ele a tarefa de convencionar o educando a escola, família ou sociedade. Contudo hoje em dia, a orientação pedagógica volta-se à constituição do cidadão além dos espaços educativos.

A elaboração deste estudo consistiu em fazer um levantamento e análise bibliográfica, acerca do tema proposto, uma vez que este trabalho caracteriza-se como um trabalho de revisão bibliográfica. Segundo Lakatos e Marconi (2001), a pesquisa bibliográfica é o procedimento básico na obtenção de dados para os trabalhos acadêmicos de modo geral.

Através da pesquisa bibliográfica procura-se explicar e discutir um tema com base em referências teóricas publicadas em livros, periódicos e etc. Busca-se conhecer e analisar as contribuições científicas quando realizadas independentemente análise teórica - como parte da investigação empírica.

\section{A juventude enquanto categoria social}

Groppo (2000) define juventude como categoria social, conjuntura social e como representação sociocultural criada pelos próprios indivíduos ou grupos analisados jovens para oferecer sentido ao 
comportamento e atitudes conferidos à juventude. Foi a partir dos anos 1950 que nasceu o conceito de cultura juvenil para assinalar o universo comportamental próprio da juventude, entretanto o conceito se desenvolveu nos anos 60 em implicação das manifestações juvenis da ocasião, ganhando novas dimensões com o conceito de conflito geracional provocado pelas transformações sociais e culturais em movimento na década.

Entende-se por cultura juvenil um sistema de valores conferidos à juventude, aos quais jovens de diversos meios $\mathrm{e}$ condições sociais aderem, se distinguindo de acordo com o grupo social e histórias de vida (Pais, 2003). Deste modo, diversas juventudes e formas de interpretá-las podem ser incorporadas em duas correntes teóricas.

A primeira corrente, a corrente geracional enfatiza o aspecto unitário da juventude, abrangendo-a como uma etapa da vida. Aqui, cultura juvenil se determina pela relativa aversão à cultura das gerações antecedentes. Em resultado, tende-se a conferir à delinquência juvenil o desajuste dos jovens ao comportamento aconselhado pelos mais velhos já que a cada geração se identificam correntes de jovens que acolhem o que existe socialmente e os que se revoltam (Pais, 2003).

De acordo com Pais (2003), a segunda corrente, chamada de classista explica a juventude a partir da representação social entendida em termos da reprodução das classes, sendo a mudança para a vida adulta determinada pelas desigualdades sociais. Aqui as culturas juvenis são oferecidas como culturas de resistência, isto é, ajustadas num contexto determinado pelas relações de classe.

Nas duas correntes o conceito de cultura juvenil está conexo ao de cultura dominante, pois uma se assinala pela oposição à cultura predominante das gerações mais velhas e outra pela aversão à cultura da classe dominante. Portanto, nas duas correntes, cultura juvenil se distingue como subcultura e como processo de internalização de regras nos procedimentos de socialização (Pais, 2003).

Deste modo, entende-se que a análise da juventude enquanto uma categoria social deve transitar entre as duas correntes citadas acima por Pais (2003), de modo a envolver os seus diferentes aspectos no significado de apreender a complexidade do fenômeno de forma genérico designado juventude.

\section{Os jovens, sua identidade e a escola como grupo social}

É comum entre jovens se unirem a grupos ou movimentos reservados num processo que influencia a constituição de suas identidades. Portanto, na procura por 
identidade e identificação, recusam os padrões vigorantes de adulto e buscam, entre pares, os que compartilham os mesmos sentimentos e ideais. A formação da identidade do jovem como um procedimento de identificação tende a ser localizado espacialmente e é estabelecido subjetivamente no jogo dos intercâmbios sociais, sendo a relação entre identidade e identificação assinalada pela afetividade (Almeida, 2006).

Atualmente são muitos os jovens que, ao apresentarem fracas relações familiares e de amizade, tomam hábitos e condutas que os fazem serem benquistos por grupos, por vezes mesmo que se tenha que tornar em algo que não são. Estes grupos de pessoas adotam um estilo próprio de vida e possuem características que as determinam, trazem valores culturais, um modo de vestir próprio, as suas próprias músicas e os seus próprios ideais políticos e éticos.

Para Maffesoli (2006), a partir disto o sujeito cria laços emocionais e conduz afetos incididos de uma sensibilidade coletiva. A identificação entre pares está vinculada, deste modo, aos domínios do sentimento, da emoção, da ideologia. A escola pode ser observada como um agrupamento social dotado de composição própria que apresenta internamente, estruturas determinadas pela sociabilidade entre seus membros.
Para Cândido (1978) citado por Maffesoli (2006), os grupos que se desenvolvem no espaço escolar se constituem de acordo com modelos ideais de comportamento. São cinco (cinco) os tipos de grupo, segundo o autor:

1 - Grupos de idade: constituídos pelos adultos (professores, gestores, funcionários) e pelos imaturos (alunos) que apresentam em comum a pouca idade e a posição subordinada dos estudantes. Este grupo pode se subdividir em diversos níveis de ensino segundo a idade;

2 - Grupos de sexo: não obstante da união do ensino para os sexos, a relação entre gêneros varia conforme a idade;

3 - Grupos associativos: compostos a partir da associação propiciada por atividades concretizadas em comum;

4 - Grupos de Status: constituídos pela estratificação própria da escola onde os membros apresentam distintas posições;

5 - Grupos de ensino: instituídos a partir da própria organização escolar, ou seja, da sala de aula (Maffesoli, 2006).

Os grupos chamados associativos se identificam ao que Maffesoli (2006) denomina tribos, distinguidos pela forma de convívio e por trazer atividades ou valores comuns são os menos estudados no ambiente escolar, ainda que presentes em todas as escolas em maior ou menor número. Idade e sexo, ainda que não sejam principais, também operam na sua 
formação. Constituindo um estilo próprio de vida como modo de autoafirmação, os grupos associativos apresentam a característica de serem inconstantes, podendo se romper ligeiramente.

Cândido (1978) citado por Maffesoli (2006) enumera três tipos de grupos associativos: a) recreativos; b) intelectuais; c) cooperativos. Os recreativos estão vinculados às práticas lúdicas na escola. Os intelectuais são desenvolvidos por pessoas que visam o aprimoramento escolar. Os cooperativos se assinalam pelo auxílio mútuo na procura de algo comum.

O símbolo da tribo urbana recomenda um processo de desindividualização atual, pois segundo Maffesoli (2006):

O caráter individualista da identidade nos princípios da Modernidade adentra em decadência nos finais do século $\mathrm{XX}$, pois enquanto a lógica egocêntrica se ampara numa identidade separada e fechada sobre si mesma, a pessoa apenas existe na relação com o outro (Maffesoli, 2006, p.15).

Deste modo, as tribos urbanas podem ser caracterizadas como um fenómeno juvenil dos grandes centros urbanos, que se vai expandindo por toda a parte. As formas como esses novos grupamentos juvenis assinalam sua inclusão social expressam o modo como às novas gerações coligam e são comprometidas pelas mudanças socioeconômicas e culturais da atualidade.

Goffman (2011) assevera que o comportamento significativo do ator social que parece involuntário depende de informações do ambiente para guiar suas atividades e parecer adequado e persuasivo. A desenvoltura do ator está vinculada, portanto, ao tempo e espaço da interação. Empregando a ideia de personalidade, percebe-se que, na escola, o jovem decodifica o papel de acordo com o ambiente e com grupo ao qual se une. Pertencer a um grupo é uma tentativa de impedir, de certo modo, o isolamento, e nesse forte investimento emocional de aderência a um grupo e sua estética, a vontade subjetiva não apresenta a mesma importância.

Estas tribos surgem num empenho de diferenciação dos jovens e evocam características que as caracterizam do resto da sociedade e que as identificam. A pertinência a um destes grupos pode ser positiva na estruturação da identidade pessoal ao avigorar sentimentos de exclusividade, de proteção, de tolerância e de partilha com os pares.

A ideia de personalidade diz reverência às máscaras inconstantes que admitem relação a diversos ambientes e tribos, a partir da inconstância que 
individualiza as relações. Os jovens podem modificar de tribo, o comportamento variando de lugar a outro, a depender de informações retiradas do cenário de ação. $\mathrm{O}$ indivíduo se ajusta aos ambientes em que se encontra e às diferentes circunstâncias do dia-a-dia (Maffesoli, 2006).

Segundo Maffesoli (1998, p.17), “a personalidade somente existe na relação com o outro". É o tempo diário dos jovens conexo às práticas de sociabilidade e lazer que decide a constituição de grupos com indivíduos de gostos parecidos. O tempo que os jovens passam unidos no espaço escolar produz atividades e formas de apreender o mundo.

Deste modo, observa-se que o ambiente escolar apresenta um papel que é a de criar um corpo coletivo, de adaptar um ethos (Maffesoli, 2006). Para Geertz (2008), ethos são os aspectos morais e estéticos de uma sociedade ou de determinada cultura, seus elementos valorativos, ou seja, é a atitude subjacente em relação a ele mesmo e ao seu mundo que a vida reflete.

O ethos é a visão de mundo de um grupo; a interpretação que oferece ao que está à volta e, desenvolvido a partir de território físico e figurado comum, concebe, um jogo de relações espaço-tempo onde à evidência está no que é próximo e no afetivo e esta existência diária está na ordem da proximidade (Geertz, 2008).
$\mathrm{Na}$ escola, os alunos instituem um contato próximo, criam vínculo afetivo e constituem um ethos como maneira de pensar comum nascido da emoção ou paixão compartilhada e do sentimento coletivo de pertença. É comum essa emoção provocar aderência a uma estética que transcorrem os setores da moda, artes, etc. e que é componente estruturante na construção da identidade. É no espaço social que se localiza, por conseguinte, formas de gerir os afetos, onde as crenças comuns são organizadas; é nele que se busca a companhia daqueles que pensam e que sentem iguais.

É este estar junto que permite a composição do ethos como forma irrefletida de moralização dos indivíduos pelo grupo. As tribos urbanas surgem da proximidade das pessoas no espaço social. Assim, como em qualquer lugar, também na escola para ser aceito no grupo o estudante serve aos interesses deste, reforçando o que é comum aos membros (Maffesoli, 2006).

Para Maffesoli (2006), pode-se pronunciar que ao indivíduo unificado obedece à pessoa heterogênea capaz de uma pluralidade de papéis. Essa percepção da ação social sinaliza o declínio do individualismo nos finais do século $\mathrm{XX}$, onde o sujeito não é, ou não é mais, mestre de si. O que não quer articular que ele não seja ator. Ele o é, de fato, contudo à maneira daquele que lê um texto escrito por outra 
pessoa.

O que pode parecer evidente é que a cultura juvenil contrapõe o que acontece em relação à absorção da cultura em geral, isto é, a cognição de valores e comportamentos que permite viver em sociedade.

Conforme Geertz (2008), o homem é um animal cativo a teias de sentido que ele mesmo teceu. Portanto, a cultura é fundamentalmente simbólica e guia a atuação social. É nesse sentido que as pessoas regulam comportamentos e atuam de forma a serem aceitos.

A cultura é componente dinâmico e a Revolução Industrial abreviou seu dinamismo. A

Indústria Cultural, produto desse processo, instituiu a cultura de massa e a relação entre culturas com o rádio, cinema, televisão, telefonia e a internet. A cultura de massa se faz em escala industrial e compreendem setores da moda, esporte, artes, etc., que influenciam o estilo da vida contemporânea, especialmente urbanos. Neste sentido vive-se atualmente o padrão estético da pluralidade cultural. A priori, os exemplos da indústria cultural admitem aos consumidores enquadrar-se em grupos com determinado senso estético e que pode atuar também como fator de desagregação.

\section{As tribos urbanas no espaço escolar}

Para a escola e os profissionais envolvidos, o problema posiciona-se na juventude, no seu individualismo de caráter hedonista e insensato, dentre outros adjetivos, que estaria motivando um desinteresse pela educação escolar. Para os jovens, a escola se demonstra afastada dos seus interesses, restringida a um dia-a-dia tedioso, com professores que pouco somam à sua formação, tornando-se cada vez mais uma obrigação indispensável, tendo em vista a pressão da família e a necessidade de ter um diploma. O que se nota hoje nas escolas é uma crise na sua relação com os jovens e professores se perguntando a que se propõe esse espaço hoje.

Entender a presença das tribos urbanas na escola é de suma importância para um melhor entendimento entre adolescentes e toda comunidade escolar, e é a partir desse entendimento que o aluno deixa de ser estigmatizado fazendo deste modo um melhor ambiente para a Escola. Quando se discorre sobre tribos urbanas deve-se lembrar de que ai se incluem questões pautadas ao gênero, a etnia e gerações.

Assim, a educação se adapta como responsável pela visão de homem na sua conjuntura histórica, no seu meio social e na sua cultura, na qual pode asseverar, que cultura sem educação não é cultura. Levando em apreço que cultura vai além de hábitos tradicionais e mesmo entre aqueles que possuem culturas idênticas, não há uma 
homogeneidade (Gomes, 2006).

Gomes (2006) coloca que a sociedade está passando por um novo período, o qual vem se configurando no conjunto da produção teórica que debate a relação entre a escola e os seus sujeitos, esse momento vem auferindo força a partir do empenho de pesquisadores da educação e também de integrantes de movimentos sociais, fazendo com que a comunidade escolar consiga um novo olhar sobre questões referentes aos processos socioculturais como a construção de identidades.

E isso é verificado a partir das experiências culturais construídas, no interior das escolas, seja a partir de algo com quem se identifique, firmando deste modo, suas identidades, socialmente estabelecidas por sua sociedade ou por meio de outros sujeitos.

Gomes (2006) afirma que de forma gradativa dentro da Educação está se desenvolvendo um movimento que a inclusão de novas questões sociais e culturais, nas quais dentre elas se abrangem o diálogo entre educação, cultura, e diversidades visam reconhecer melhor os enredos de relacionamento existentes nas escolas. Contudo, infelizmente, não são todas as comunidades educacionais que se interessam por esse assunto.

Krenak (2006) acha importante refletir e debater sobre a formação de tribos urbanas nas escolas, pois faz com que os sujeitos que ali atuam desenvolvam um conceito mais tolerante, que vai além dos limites do que foi estabelecido socialmente na vida de todos. A ação específica da escola colabora inteiramente para o reforço das características uniformizantes da cultura, especialmente da chamada cultura dominante, podendo existir uma atenuação correlata dos princípios das culturas adquiridas a partir das chamadas novas identidades, que seriam aquelas que foram absorvidas pelos jovens não pelas construções sociais que thes foram conferidas, entretanto pelas culturas elegidas por vontade própria.

As tribos urbanas estão presentes a partir da estética, dos gostos musicais, de ideologias políticas, religiosas e elas são constituídas especialmente na adolescência e se distendem por algum tempo ou até mesmo por toda a vida, e o primeiro espaço no qual podem ser observadas sua existência são as escolas, tanto públicas como particulares.

Porém, tanto os professores como seus especialistas em sua maior parte estigmatizam esses estudantes, por não trazerem um conhecimento apropriado sobre as diversidades que envolvem os mesmos. Esses grupos não se enquadram num padrão normativo e estão cada vez mais visíveis entre os jovens, portanto, o papel da escola é preparar o aluno para 
serem cidadãos críticos, solidários e democráticos numa sociedade que se baseia na diversidade.

É na escola que se desenvolvem as primeiras identidades que podem se delongar pela vida toda, e que podem causar efeitos positivos ou não, dependendo do grau de aceitamento do outro. A grande parte dos adolescentes gosta de se refletir no outro para estabelecer as suas novas identidades, especialmente naqueles que eles analisam ídolos ou até mesmo da cultura de outros países, a qual eles se identificam.

\section{O orientador educacional: origens e funções}

Segundo Grinspun (2011), a função do Orientação Educacional teve princípio em 1924, no Liceu de Artes e Ofícios de São Paulo, também com o papel de Orientação Vocacional. A primeira tentativa de Orientação Educacional no Brasil deve-se a Lourenço Filho, que quando diretor do Departamento de Educação do Estado de São Paulo estabeleceu o Serviço de Orientação Profissional e Educacional, em 1931, o qual apresentava como maior objetivo, gerir o indivíduo na seleção de seu espaço social pela profissão.

Ainda para o autor, foi na Lei de Diretrizes e Bases da educação no ${ }^{\circ} 4024$ de 1961 que o Orientador Educacional vem com o papel de colaborar para a formação completa da individualidade do adolescente, para seu amoldamento pessoal e social. Suas fundamentais áreas de alcance seriam as orientações escolar, psicológica, profissional, da saúde, recreativa e familiar. Já na Lei de Diretrizes e Bases da educação no 5692 de 1971, a Orientação Educacional adota um papel essencial, sendo a área da Orientação Vocacional a mais distinta para atender as finalidades de ensino da própria lei.

Na década de 1980, o orientador vai deixando as funções de acolher os alunos problemas, de psicólogo e facilitador de aprendizagem e vai com o tempo adotando com mais comando técnico ao seu compromisso político com a escola.

Nesse período, a orientação apresentava papel intermediário junto aos demais professores da escola, procurando deste modo o resgate de uma educação de qualidade nas escolas. Da ênfase ao individual de antes, passou-se, a avigorar o aspecto grupal, sem deixar de levar em conta que este é formado por pessoas com pensamentos e contextos sociais caracterizados que as levam a pensar de maneira própria sobre as questões que lhes cercam, devendo elas chegarem a realizações bem-sucedidas (Grinspun, 2011, p. 27).

Hoje em dia, o Orientador educacional não opera mais por ser uma 
carreira que deva existir pelo compromisso, pois na Lei 9394/96 não existe a obrigatoriedade da Orientação, contudo por essencial consciência profissional, o orientador traz ambiente próprio junto aos demais atores da escola para um trabalho pedagógico coerente, compreendendo criticamente as relações que se colocam no processo educacional.

O orientador educacional tem que convir para esse novo período, no qual a educação lida com o real e suas expectativas. O fundamental papel da Orientação será auxiliar o educando na construção de uma cidadania crítica, e a escola, na disposição e consolidação de seu projeto pedagógico.

\section{O orientador educacional no espaço escolar e as tribos urbanas}

A orientação pedagógica está denominada como fazendo parte da educação e por esse motivo deve refletir, atualmente, nas dimensões sociais, culturais, políticas e econômicas na qual ela acontece. Por esse causa, devem-se determinar as tarefas de um orientador engajado com as transformações sociais, com a do período histórico em que está inserido.

Segundo Maia e Garcia (1990), a orientação pedagógica é concebida como um processo sistemático e contínuo que se diferencia por ser um amparo profissional alcançado por meio de métodos e técnicas pedagógicas ou psicológicas, exercida direta ou indiretamente sobre os alunos, levando-os a informação de suas características pessoais e do espaço sócio cultural, a fim de que possam tomar decisões adequadas às melhores perspectivas de seu desenvolvimento pessoal e social, tornando-se cada vez mais indispensável.

Maia e Garcia (1990) citam que a orientação educacional é também analisada uma ação respeitável no avanço da qualidade dos moldes educacionais em países nos quais se designam recursos expressivos à educação e impõe-se, no meio social, não apenas como um recurso somatizado para o aperfeiçoamento da escola, contudo, sim, como um fator indispensável para responder às precisões do desenvolvimento pessoal e social do educando.

Pode-se pronunciar que, em certos períodos, a função do orientador educacional é conservador, na medida em que convenciona o estudante à escola e prepara-o para sua adaptação na sociedade e para a realidade em que vive. Tanto a escola quanto a sociedade se deparam apresentando igualdade de oportunidades para todos, contudo, como os sujeitos são distintos uns dos outros, não apenas em relação as suas habilidades naturais como 
ao esforço efetivado, nem todos conseguem alcançar os mesmos frutos e isso é corretamente comum.

Para Maia e Garcia (1990), o orientador educacional não é um trabalhador exclusivo da educação, uma vez que ele pertence a um grupo de trabalhadores da educação que refletem juntos sobre a sociedade, sobre a relação educação e sociedade. O orientador educacional ao se deparar com a formação de tribos urbanas dentro da escola deve fazer com que os alunos reflitam sobre o que faz ele feliz tanto no campo individual como no coletivo.

De acordo com Giacaglia e Penteado (2003), o melhor caminho para se trabalhar é em conjunto, movimentando a escola, a família, e a comunidade, para que ocorra uma verificação grupal da realidade à quais todos pertencem. Enquanto alguns orientadores estão concentrados em instituir uma atmosfera facilitadora de relações, outros instituem um clima facilitador de aprendizagem, ficando deste modo claro, para eles, qual a exata função da escola. Para eles, a escola não é espaço em que os indivíduos vão para viver períodos agradáveis, contudo sim uma instituição que tem que administrar a cultura e designar novos conhecimentos.

$\mathrm{O}$ orientador educacional tem recebido ponto de vista variável, pois apresenta papel fundamental em atuar com os estudantes. Assim sendo é que a orientação é determinada como um procedimento pelo qual o orientador auxilia o aluno, na escola a tomar consciência de seus valores e dificuldades, consolidando, especialmente por meio do estudo, sua efetivação em todas as suas composições e em todos os planos de vida. O mesmo ainda faz levantamentos de dados, desempenha sessões de orientação e de aconselhamento e realiza uma série de funções de maior ou menor importância, pautadas com a percepção do acolhimento ao aluno.

Dentre todas essas ações o aconselhamento tem sido avaliado como a fundamental e mais importante. Entretanto, a fundamentação, capacidade e resultado de tal função na escola têm sido vastamente questionados hoje em dia, em face de dificuldade de o orientador demonstrar, objetivamente, que, dedicando grande parte do seu tempo e contribui do melhor modo aceitável para a observação da problemática do aluno (Giacaglia \& Penteado, 2003).

Conforme Grinspun (2011), os padrões e técnicas de aconselhamento empregado em orientação desenvolveramse na esfera da psicoterapia, e de maneira implícita adquirem a noção de que o sujeito e não o espaço em que faz parte é que deve transformar-se. Observam-se com facilidade a adaptação de tal compreensão em posições assumidas pelo orientador educacional na escola, posições estas que 
obedecem a expectativas de pessoas que compartilham do processo educativo.

Lück (2010) discorre que o aconselhamento é mais usualmente usado em eventos relacionados com indisciplina e a prática habitual é do educando ser conduzido à orientação educacional com a expectativa subentendida de que o mesmo seja transformado, corrigido. A suposição implícita é de que o estudante está o motivo do problema. Tal método não distingue que, muitas vezes, conduta imprópria do educando são originados, dentre outros, por disfunções ambientais como, por exemplo, currículos e programas inadequados às suas precisões e condições particulares, regras inalteráveis, ou indiferença de professores e adultos em geral à personalidade do aluno.

Além da parcialidade com que assiste a posição do educando, tal posição assumida incide em desacerto por chocar-se com os princípios do próprio aconselhamento quanto à concordância e apreensão do aluno. Os padrões e técnicas de aconselhamento desenvolveram-se, sobretudo mediante seu aproveitamento com clientes adultos e voluntários. A viabilidade de sua aplicação com outro tipo de população na escola, a criança e o adolescente comumente não natural, carece ser demonstrada.

O relacionamento espontaneamente diferente entre orientador e aluno deixa de comunicar no educando como tal, principalmente na cultura em que o adulto é naturalmente observado como autoridade pelo jovem, independentemente da posição que ocupe em relação a ela (Lück, 2010).

$\mathrm{O}$ aconselhamento pessoal e mesmo em grupo, como forma fundamental de atuação em orientação, sujeita a uma dimensão relativamente pequena de estudantes por orientador educacional. Numa escola com números altos de alunos em proporção a orientadores educacionais, em que se sigam as funções de aconselhamento como forma central de ação, acontece seguramente o atendimento de uns poucos alunos, ficando a maior parte deles sem receber os melhoramentos da orientação educacional (Lück, 2010).

Além disso, ainda, pressionados pelo tempo restrita dada à sobrecarga de alunos, tentará o orientador educacional a sintetizar a duração e o número das sessões de aconselhamento com cada aluno e, inadvertidamente, o orientador poderá obrigar um ajustamento antecipado e artificial.

Para Lück (2010), o atendimento individual ao aluno, que vem diferenciando a orientação pedagógica, fundamenta-se na finalidade de que os jovens apresentam necessidades especiais e que os professores não estão aparelhados ou não tem condições para atendê-las. Conforme esse enfoque o orientador educacional oferece serviços na medida em que surgem as necessidades. 
Tal compreensão de prestação de serviços e acolhimento direto ao aluno, segundo a situação de necessidades psicológicas e emocionais parece ter provocado uma transformação na concepção e definição do papel do professor em relação ao educando. Observa-se, que, quando o professor apreende que algum estudante seu traz dificuldades especiais, encaminha-o para o orientador educacional a quem transfere a responsabilidade de resolvê-las.

O professor é figura fundamental no desenvolvimento do aluno. É ele quem forma no estudante o desejo ou aborrecimento pela escola; a motivação ou não pelos estudos; o acordo do valor ou insignificância dos campos e objetivos de estudo; a percepção de sua competência de aprender, de sua importância como pessoa, etc. Da propriedade do relacionamento interpessoal professor-aluno, de responsabilidade do primeiro, depende, dentre outras coisas, a adaptação emocional do aluno em sala de aula e na escola. Assim sendo, não se concebe o efeito de uma ação para sanar dificuldades dos estudantes em sala de aula sem o conhecimento do professor.

Em vista dos problemas divulgados, recomenda-se que o orientador educacional adquira funções de auxílio ao professor, aos pais, às pessoas da escola com as quais os alunos conservam contatos expressivos, no sentido de estes se tornem mais organizados para apreender e atender às necessidades dos alunos, tanto com relação aos aspectos cognitivos e psicomotores, como aos afetivos.

\section{Considerações finais}

Novas formas de comportamento e de agrupamentos e a natural procura de identidade e identificação entre jovens têm sido assunto de reflexão especialmente no que diz respeito à socialização e sociabilidade no espaço escolar onde nas sociedades contemporâneas, os jovens vivem grande parte do seu tempo. A aproximação que institui a construção de uma identidade de grupo nasce a partir de três fatores, a estética formada pela indústria cultural, as redes sociais a que as pessoas que tem acesso e ideais compartilhados.

Essas formas de aproximação é o que esclarece o surgimento das tribos urbanas nos espaços urbanos e na escola que pode ser tanto de ordem real, proximidade física, espacial e temporal, quanto simbólica. A inclusão nos grupos a partir das redes sociais se oferece no fato de se conhecer alguém que apresenta outro alguém. Deste modo, as tribos se desenvolvem a partir de uma familiaridade pré-estabelecida, num círculo de relações que valoriza o que é próximo, conhecido. 
A partilha de determinada estética é estrutura de aproximação na composição dos grupos. Nesse significado, os grupos se formam a partir de disposições estéticas da cultura juvenil decorridas da indústria cultural no seu dia-a-dia. Essa estética é observável no visual, na aparência e comportamento das tribos, meios de identificar os que sentem ou refletem em comum; os que compartilham os mesmos gostos, jeitos de ser e de viver ou o mesmo estilo.

Os ideais, quando repartidos, servem como mecanismos de manutenção da tribo e despertam uma sentimentalização coletiva que gera o auxílio recíproco na procura ora do rendimento escolar ora de lazer, constituindo determinada ética de grupo. No espaço escolar observa-se a territorialidade instituída entre os que aceitam a cultura escolar e os que a renunciam.

O núcleo de atenção máxima da escola deve ser o aluno. A escola existe em função dele, e, assim sendo, para ele. A sua coordenação em quaisquer dos seus aspectos, deve apresentar em vista a importância do fim precípuo a que a escola se designa: a concepção de condições e de circunstâncias adequadas ao bem estar emocional do aluno e o seu desenvolvimento em todos os significados: cognitivo, psicomotor e afetivo, a fim de que o mesmo adquira aptidões, conhecimentos e costumes que lhe admitam fazer face às precisões fundamentais e existenciais.

$\mathrm{Na}$ solicitação destas condições e circunstâncias um dos fatores mais determinantes é o orientador educacional. Suas atitudes, práticas, papéis promovem um choque expressivo no jovem, pois elas implicam na representação que os estudantes cultivam da escola, no processo educativo em geral, na imagem de si mesmo, e, é claro, em aspectos especiais de sua aprendizagem. Destarte, toda atenção deve ser oferecida ao desenvolvimento de atitudes, habilidades e conhecimento do orientador educacional para que possa originar um processo educativo ressaltante.

\section{Referências}

Almeida, M. I. M. de (2006). "Zoar" e "ficar": novos termos da sociabilidade jovem. In: Almeida, M. I. M. de; \& Eugenio, F. (orgs.). Culturas jovens: novos mapas do afeto. Rio de Janeiro, Jorge Zahar.

Brasil (1996). Lei no 9394/96 de 20 de dezembro de 96. Lei de Diretrizes e Bases da Educação Nacional. Brasília: Senado. 
Geertz, C. (2008). A interpretação das culturas. Rio de Janeiro, LTC.

Giacaglia L. R. A. \& Penteado, W. M. A. (2003). Orientação educacional na prática: princípios, técnicas, instrumentos. São Paulo, Pioneira Educação.

Goffman, E. (2011). A representação do eu na vida cotidiana. Petrópolis, Vozes.

Gomes, N. L. (2006). Escola e diversidade étnico-cultural: um diálogo possível. Belo Horizonte, UFMG, Juarez Dayrell.

Grinspun, M. P. S. Z. (2011). A orientação educacional: conflito de paradigmas e alternativas para a escola. São Paulo, Cortez.

Groppo, L. A. (2000). Juventude: ensaios sobre sociologia e história das juventudes modernas. Rio de Janeiro, Difel.

Krenak, A. (2006) A educação indígena: as relações entre cultura e identidade. In:. Dayrell, Juarez (Org). Múltiplos Olhares-Sobre educação e cultura. Belo Horizonte, UFMG.

Lakatos, E. M. \& Marconi, M. A. (2001). Ciência e conhecimento científico. In: Fundamentos da Metodologia Científica. São Paulo, Atlas.

Lück, H. (2010). Gestão Educacional: Uma Questão Paradigmática. Petrópolis, Vozes.

Maia, E. M. \& Garcia, R. L. (1990). Uma Orientação Educacional Nova para uma Nova Escola. São Paulo, Loyola.

Maffesoli, M. (2006). Tempo das tribos: o declínio do individualismo nas sociedades de massa. Rio de Janeiro, Forense Universitária.

Pais, J. M. (2003). Culturas juvenis. Lisboa, Imprensa Nacional-Casa da Moeda.

\section{O autor:}

Anderson Oramisio Santos é especialista em Psicopedagogia. Mestre e Doutorando em Educação pela Universidade Federal de Uberlândia, e-mail: oramisio@hotmail.com

Recebido em: 19/07/2017.

Aprovado em: 29/12/2017. 